\title{
CONSIDERACIONES SOBRE LA INSTRUMENTACIÓN PRÁCTICA DE LA POLÍTICA MONETARIA
}

Moisés J. Schwartz Rosenthal ${ }^{1}$

\author{
O ctubre de 1998 \\ D ocumento de Investigación No. 9804 \\ Dirección General de Investigación Económica \\ BANCO DE MÉXICO
}

\begin{abstract}
${ }^{1}$ Se agradecen los comentarios de Agustín Carstens, Alejandro Díaz de León, Pascual O’D ogherty, Alejandro Werner y de los participantes del Seminario de la Dirección de Estudios Económicos del Banco de México, así como la ayuda de D aniel Backal en la elaboración de este documento. Las opiniones contenidas en este trabajo corresponden exclusivamente al autor y no necesariamente representan el punto de vista del Banco de México.
\end{abstract}




\title{
CONSIDERACIONES SOBRE LA INST RUMENTACIÓN PRÁCTICA DE LA POLÍTICA MONETARIA
}

\author{
Moisés J. Schwartz Rosenthal \\ O ctubre de 1998 \\ Documento de Investigación No. 9804
}

\begin{abstract}
RESUMEN
Durante los últimos años la instrumentación de la política monetaria por diversos bancos centrales ha evolucionado hacia una mayor utilización de los mecanismos de mercado. La cada vez menor dependencia de la política monetaria de instrumentos tales como los requerimientos de reserva en el banco central, ha impuesto nuevos retos a las autoridades monetarias. Este documento argumenta que la conjunción de medidas del banco central orientadas a influir sobre las condiciones monetarias en el mercado de dinero y su capacidad de compensar de manera oportuna movimientos erráticos de las curvas de demanda y de oferta de base monetaria, constituyen los principales elementos para la adecuada instrumentación de la política monetaria. La evidencia empírica de varios países, incluyendo a México, indica que el hecho de que el banco central logre garantizar la existencia, en un momento dado, de una demanda por liquidez de la banca que le permita a ésta hacer frente a sus compromisos de pago, resulta fundamental para un adecuado manejo monetario.
\end{abstract}




\section{CONSIDERACIONES SOBRE LA INST RUMENTACIÓN PRÁCTICA DE LA POLÍTICA MONETARIA}

\section{Introducción}

Durante los últimos años la instrumentación de la política monetaria por diversos bancos centrales ha evolucionado hacia una mayor utilización de los mecanismos de mercado. Los bancos centrales han ampliado el número de instrumentos disponibles para la ejecución de la política monetaria, han disminuido los niveles de los requerimientos de reserva -- entendidos éstos como la exigencia de mantener cierto porcentaje de los pasivos de la banca en la forma de depósitos en el banco central --, han aumentado la flexibilidad en el manejo de la liquidez y han mejorado la transparencia y la comunicación de las intenciones de política.

En la actualidad, un número importante de bancos centrales lleva a cabo la política monetaria mediante la utilización de instrumentos de mercado, buscando ejercer cierta influencia sobre las tasas de interés de corto plazo. Esto último con el objeto de dar inicio al llamado mecanismo de transmisión de la política monetaria. A través de dicho mecanismo, las acciones del banco central tienen un efecto sobre la demanda agregada y, a la postre, sobre la evolución de los precios.

En este trabajo se busca analizar la forma en la que los bancos centrales han venido instrumentando su política monetaria en los últimos años. Parte importante del análisis se centra en la cada vez menor utilización de los requerimientos de reserva como instrumento de política y en los retos que dicha medida impone a las autoridades monetarias. En específico, el trabajo argumenta que la conjunción de medidas del banco central orientadas a influir sobre las condiciones monetarias en el mercado de dinero y su capacidad de compensar de manera oportuna movimientos erráticos de las curvas de demanda y de oferta de base monetaria, constituyen los principales elementos para la adecuada instrumentación de la política monetaria. La evidencia empírica de varios países, incluyendo a México, indica que el hecho de que el banco central logre garantizar la existencia, en un momento dado, de una demanda por liquidez ${ }^{2}$ de la banca que le permita a ésta hacer frente a sus compromisos de pago, resulta fundamental para un adecuado manejo monetario.

Gran parte de la literatura que ha abordado el tema de la instrumentación de la política monetaria se ha orientado a determinar cual debe ser el objetivo final de la política y a analizar en que contexto un objetivo intermedio en particular resulta más útil que otro. Mucho se ha escrito sobre la conveniencia de adoptar al tipo de cambio, a las tasas de interés 0 a la evolución de algún agregado monetario como objetivo intermedio de la

\footnotetext{
${ }^{2}$ Liquidez y base monetaria se utilizarán indistintamente a lo largo del documento.
} 
política monetaria. Más aún, recientemente, a la luz del cambiante entorno en el que operan los bancos centrales, una nueva corriente tanto académica como empírica, ha propuesto mayor flexibilidad para la autoridad monetaria en la ejecución de su política, mediante la definición explícita de metas sobre la inflación para períodos de tiempo determinados, quedando a su discreción la elección del método más apropiado para su consecución ${ }^{3}$.

Si bien la definición de un objetivo intermedio o del objetivo final de la política monetaria representan aspectos cruciales para la adecuada instrumentación de la política monetaria, también debe reconocerse que la forma y los instrumentos mediante los cuales los bancos centrales operan en el mercado tienen influencias directas no sólo sobre la organización y el funcionamiento de los mercados de dinero y capitales, sino también sobre la volatilidad de los precios de los activos financieros. Más aún, el claro entendimiento de la forma en que operan los bancos centrales, ayuda a dar respuesta a diversas interrogantes entorno al mecanismo de transmisión de la política monetaria.

El documento se encuentra organizado de la siguiente manera. En la siguiente sección se realiza un breve repaso de los principales elementos que conforman el llamado mecanismo de transmisión de la política monetaria. Esto con el objeto de situar dentro de este proceso la actuación del banco central en el mercado de dinero. La tercera sección hace una revisión de los distintos instrumentos de política monetaria. En particular, se hace un énfasis especial en la cada vez menor utilización de los requerimientos de reserva en el banco central como instrumento de política monetaria. El caso de México se analiza en detalle. La cuarta sección trata sobre la utilización de señales por parte de la autoridad monetaria. Se argumenta que si bien el envío de señales del banco central sobre su postura de política monetaria no es por sí mismo un instrumento mediante el cual la autoridad monetaria afecte la liquidez de la economía, las señales pueden propiciar acciones de los participantes del mercado de dinero tales que generen movimientos en las tasas de interés similares a los que se presentarían en caso de registrarse modificaciones en la liquidez del sistema. La quinta sección presenta algunas consideraciones sobre el abandono de la utilización de los requerimientos de reserva como instrumento de política monetaria y el impacto de esta medida sobre la conducción de dicha política. En específico, se analiza la instrumentación de la política monetaria en ausencia de requerimientos de reserva en un contexto de equilibrio en el mercado de dinero, y se determinan las condiciones que garantizan un adecuado manejo monetario. Como se señaló con anterioridad, se argumenta que parte fundamental del control monetario del banco central depende de la existencia, en un momento dado, de una demanda por liquidez de la banca, que le permita a las instituciones de crédito hacer frente a sus compromisos de pago. Dicha demanda puede quedar correspondida por una demanda de reservas bancarias en el banco central por un cierto período de tiempo, el cual inclusive podría ser de tan sólo unos instantes, o bien manifestarse como una demanda por liquidez en el mercado de dinero sin tener como contrapartida una demanda por reservas en el banco central. La eliminación de los requerimientos de reserva tradicionales implica que

3 Ver por ejemplo, Leiderman y Svensson (1995) y Mateos y Schwartz (1997). 
la demanda por liquidez señalada se determine por factores tales como las características del sistema de pagos de la economía y por las medidas de política que establezca la autoridad monetaria que afecten los incentivos de los bancos para mantener depósitos en el banco central. La interacción entre la oferta de liquidez y la demanda señalada, determinará la tasa de interés de corto plazo, dando lugar al primer eslabón del mecanismo de transmisión de la política monetaria. La última sección presenta algunas conclusiones.

\section{Mecanismo de Transmisión de la Política Monetaria}

El mecanismo de transmisión de la política monetaria se refiere al proceso mediante el cual las acciones de política del banco central afectan a la demanda agregada y a la inflación. El proceso del mecanismo de transmisión surge a partir del momento en que el banco central actúa en el mercado de dinero, y sus acciones tienen un efecto sobre las tasas de interés de corto plaz $0^{4}$. El efecto de estas tasas de interés sobre las de más largo plazo y sobre el precio de otros activos, que pudieran tener un impacto sobre la demanda agregada y por ende sobre los precios, no es del todo predecible, así como tampoco lo son los rezagos con que este efecto pudiera darse. Este efecto dependerá, en gran parte, de la estructura financiera de cada país, y de su entorno macroeconómico. El cuadro 1 muestra la secuencia de eventos que da lugar al mecanismo de transmisión.

\section{Cuadro 1}

\section{Mecanismo de Transmisión de la Política Monetaria}

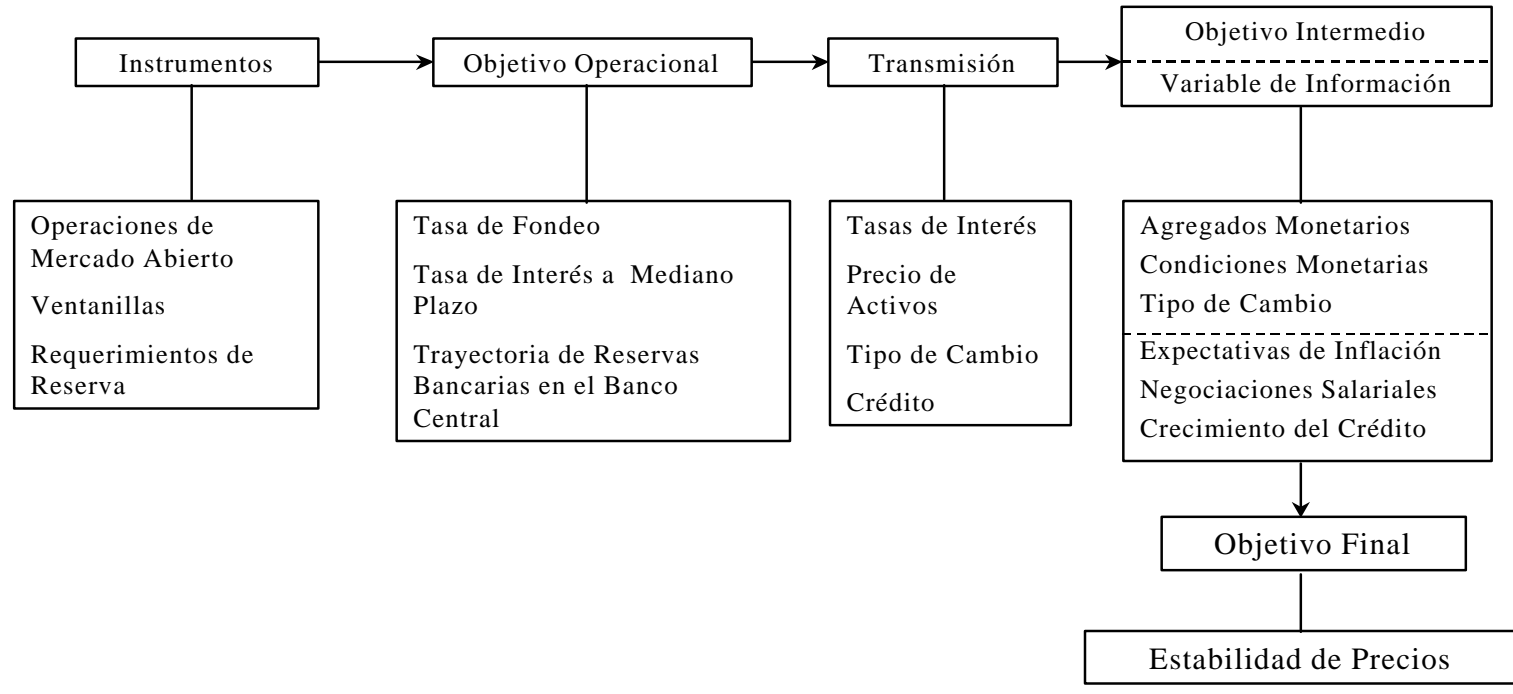

${ }^{4}$ Tasa de interés de corto plazo y tasa de fondeo se utilizarán indistintamente a lo largo del documento. 
La secuencia del mecanismo de transmisión comienza con los instrumentos de política monetaria que utiliza el banco central. A través de estos instrumentos el banco central afecta la oferta de base monetaria en el mercado de dinero e influye sobre su demanda. Entre los instrumentos más utilizados por los bancos centrales se encuentran las operaciones de mercado abierto, el establecimiento de ventanillas para proveer o retirar liquidez a iniciativa de los participantes del mercado y los requerimientos de reserva.

Parte crucial de esta primera etapa del mecanismo de transmisión es que el banco central pueda propiciar que la banca, a nivel sistémico, enfrente excesos o faltantes de base monetaria. Al enfrentar una posición de liquidez distinta a la deseada, los bancos, con el objeto de minimizar los costos en los que incurrirían si permanecen con los referidos excesos o faltantes de base monetaria, llevan a cabo acciones en el mercado de dinero que buscan alcanzar la posición de liquidez deseada. Los excedentes de liquidez redundan en una pérdida para las instituciones de crédito por el hecho de que éstas incurren en el costo de oportunidad de no otorgar dicho excedente en forma de financiamiento. Por su parte, los faltantes de liquidez generan un costo para los bancos, el cual, en buena medida, estará dado por la posibilidad y los términos en que la banca pueda incurrir en sobregiro en sus cuentas en el banco central. Las acciones realizadas por los bancos en el mercado de dinero con el objeto de alcanzar la posición de liquidez deseada, tienen un impacto sobre el objetivo operacional del banco central, el cual en ocasiones ha sido la trayectoria de reservas bancarias en el banco central, alguna tasa de interés de mediano plazo o la tasa de fondeo. Variaciones en la tasa de fondeo por ejemplo, repercuten a su vez sobre el resto de las tasas de interés y el tipo de cambio.

Las acciones que realiza el banco central con el objeto de alcanzar su objetivo operacional propician la consecución de algún objetivo intermedio que pudiera tener la autoridad monetaria o bien, afectan la trayectoria de alguna variable que otorgue información sobre la evolución futura del objetivo final, que por lo general es alguna meta de inflación para cierto período de tiempo. La consecución del objetivo intermedio o la trayectoria observada de las variables de información, pueden revelar con cierto grado de certeza si se alcanzará o no el objetivo final de la autoridad monetaria ${ }^{6}$.

Los objetivos intermedios son variables más fácilmente controlables por la autoridad monetaria, o que se observan con mayor frecuencia que el objetivo final, y que a la vez guardan una relación estrecha con este último. De tal forma que la consecución del objetivo intermedio señala una mayor posibilidad de cumplir con el objetivo final. Entre los principales objetivos intermedios destacan la evolución de algún agregado monetario, el comportamiento de algún índice de condiciones monetarias ${ }^{7}$ y el nivel del tipo de cambio. De igual manera, las variables de información, si bien no representan objetivos

\footnotetext{
5 Esto se analiza en detalle más adelante.

${ }^{6}$ Si bien la política monetaria puede orientarse hacia la consecución de distintos objetivos, existe consenso en que la mayor contribución posible de la política monetaria al desarrollo económico es abocarse hacia un objetivo de estabilidad de precios.

7 Ver por ejemplo, Ericsson y Kerbeshian (1997) y Freedman (1994).
} 
determinados públicamente por la autoridad monetaria, brindan información de qué tan probable es o no alcanzar el objetivo final. Las variables de información más utilizadas son alguna medida de expectativas de inflación, los resultados de las negociaciones salariales y el crecimiento del crédito bancario.

La mayoría de los bancos centrales llegaron a utilizar en algún momento, como parte fundamental de la instrumentación de la política monetaria, a los objetivos intermedios. Sin embargo, la cada vez menor relación observada entre el comportamiento de los objetivos intermedios y la evolución de los precios ha redundado, en muchos casos, en su total abandono, y en la utilización más intensiva de las variables de información con el objeto de alcanzar el fin último de la política monetaria. Si bien en algunos casos los objetivos intermedios no han sido del todo abandonados, su efectividad como herramienta de política monetaria, y por ende el énfasis en su utilización por los bancos centrales, se ha visto disminuida ${ }^{8}$.

Los canales por los cuales ocurre la transmisión de la política monetaria han sido ampliamente analizados por la literatura económica ${ }^{9}$. Existen básicamente cuatro canales a través de los cuales el mecanismo de transmisión puede darse. El canal tradicional se refiere al efecto directo de la política monetaria sobre las tasas de interés. La influencia sobre el comportamiento de las tasas de interés repercute sobre las decisiones de inversión y ahorro y por consiguiente sobre la demanda agregada y los precios. Variaciones en las tasas de interés de corto plazo redundan en cambios en toda la curva de tasas de interés, inclusive en las de largo plazo, que afectan las decisiones de inversión y de la adquisición de bienes duraderos.

El segundo canal de transmisión ocurre a través del impacto de las tasas de interés sobre los precios de los activos, tales como los bonos, las acciones bursátiles y los bienes raíces. El impacto de la política monetaria sobre el precio de estos activos puede afectar las decisiones de gasto de las familias y de las empresas.

El tercer canal se da a través del tipo de cambio. En este escenario, la política monetaria afecta las tasas de interés, y por consiguiente se ejerce cierta influencia sobre el tipo de cambio. Por ejemplo, en un régimen de flotación del tipo de cambio, una política monetaria restrictiva presiona al alza las tasas de interés, lo cual puede propiciar una apreciación del tipo de cambio. Por su parte, la apreciación de la moneda tiene un impacto sobre las decisiones de gasto entre bienes producidos internamente y en el exterior, afectándose así la demanda agregada y por consiguiente los precios. Más aún, ajustes del tipo de cambio pueden tener un impacto directo sobre la inflación sin que necesariamente tenga que afectarse en una primera instancia a la demanda agregada. Tal sería el caso por ejemplo, en el que las empresas tuvieran deuda denominada en moneda extranjera 0 en el que su producción requiriera de insumos importados. En la situación

\footnotetext{
8 Tal es el caso del banco central de Alemania.

9 Para una explicación más detallada ver Mishkin (1996).
} 
referida sería de esperarse que parte del mayor costo de la divisa extranjera fuera trasladado por las empresas al precio de venta de su producto ${ }^{10}$.

El cuarto canal del mecanismo de transmisión se da a través del efecto de la política monetaria sobre la disponibilidad del crédito. Una política monetaria más expansiva redunda en mayores disponibilidades de crédito en la economía. Por otra parte, una restricción monetaria no sólo puede reflejarse en mayores tasas de interés que disminuyan la cantidad demandada de crédito, sino también en una menor oferta de fondos prestables por parte de las instituciones crediticias, por considerar éstas que las mayores tasas de interés pueden dar lugar a inversiones más riesgosas de los tomadores de crédito. La mayor o menor disponibilidad de crédito en la economía tiene un efecto sobre la demanda agregada y la inflación.

Es de esperarse que la estructura financiera y el entorno macroeconómico de cada país, determinen la importancia de cada uno de los canales de transmisión de la política monetaria. Por otra parte, cabe agregar, que si bien algunas partes del mecanismo de transmisión han sido más estudiadas que otras ${ }^{11}$, el análisis detallado del proceso de dicho mecanismo representa una tarea prioritaria para los bancos centrales.

\section{Selección de Instrumentos}

Parte fundamental del manejo de la liquidez implica compensar en la medida necesaria las variaciones exógenas de base monetaria que se presenten en el mercado de dinero. Esto último con el objeto de que el equilibrio en dicho mercado se alcance de manera ordenada. Para comprender lo anterior resulta útil analizar brevemente los principales elementos del balance de un banco central.

\section{Cuadro 2 \\ Balance Simplificado de un Banco Central}

\begin{tabular}{|c|c|}
\hline Activos & Pasivos \\
\hline Reserva Internacional & Billetes y Monedas \\
\hline - Crédito Interno Neto & 口 Depósitos Bancarios \\
\hline $\begin{array}{l}\text { Fuentes de la Base Monetaria } \\
\text { (O ferta de Base) }\end{array}$ & $\begin{array}{l}\text { Usos de la Base Monetaria } \\
\text { (D emanda de Base) }\end{array}$ \\
\hline
\end{tabular}

El balance del banco central, por el lado de los activos (fuentes de la base monetaria), incluye a las reservas internacionales y al crédito interno neto del instituto emisor. El crédito interno neto esta conformado por el financiamiento otorgado por el banco

\footnotetext{
${ }^{10}$ En algunos episodios devaluatorios se ha observado que aún en el caso en que el ajuste cambiario no justifique un aumento inmediato en los precios, la expectativa de que la devaluación de la moneda llegará a afectar el ritmo de crecimiento futuro de los precios, propicia que el ajuste cambiario se traduzca rápidamente en mayor inflación.

11 Ver por ejemplo, Copelman y Werner (1996), D uguay (1994), Greenham (1997) y Taylor (1995).
} 
central al gobierno y a los bancos comerciales. Por su parte, los pasivos del banco central (usos de la base monetaria) incluyen a los billetes y monedas y a los depósitos de la banca en el banco central. De tal forma que variaciones en las reservas internacionales, producto de la intervención del banco central en el mercado cambiario y modificaciones en el crédito interno neto del instituto emisor, deben tener como contrapartida, cambios en la demanda de billetes y monedas y/ o variaciones en los depósitos bancarios en el banco central.

De esta manera, el adecuado manejo de la liquidez por parte del banco central, consiste precisamente en determinar el monto de su crédito interno neto, con el objeto de que su intervención en el mercado de dinero garantice la consecución de su objetivo operacional ${ }^{12}$. El cuadro 3 muestra la interacción de los distintos elementos del balance del banco central y la importancia del crédito interno neto como variable de ajuste para que el equilibrio en el mercado de dinero resulte congruente con el alcance del objetivo operacional del banco central.

\section{Cuadro 3}

\begin{tabular}{|c|}
$\begin{array}{c}\text { Cambio en la } \\
\text { Oferta de Base } \\
\text { Monetaria }\end{array}=\begin{array}{c}\text { Cambio en la } \\
\text { Demanda por Base } \\
\text { Monetaria }\end{array}$ \\
\hline
\end{tabular}

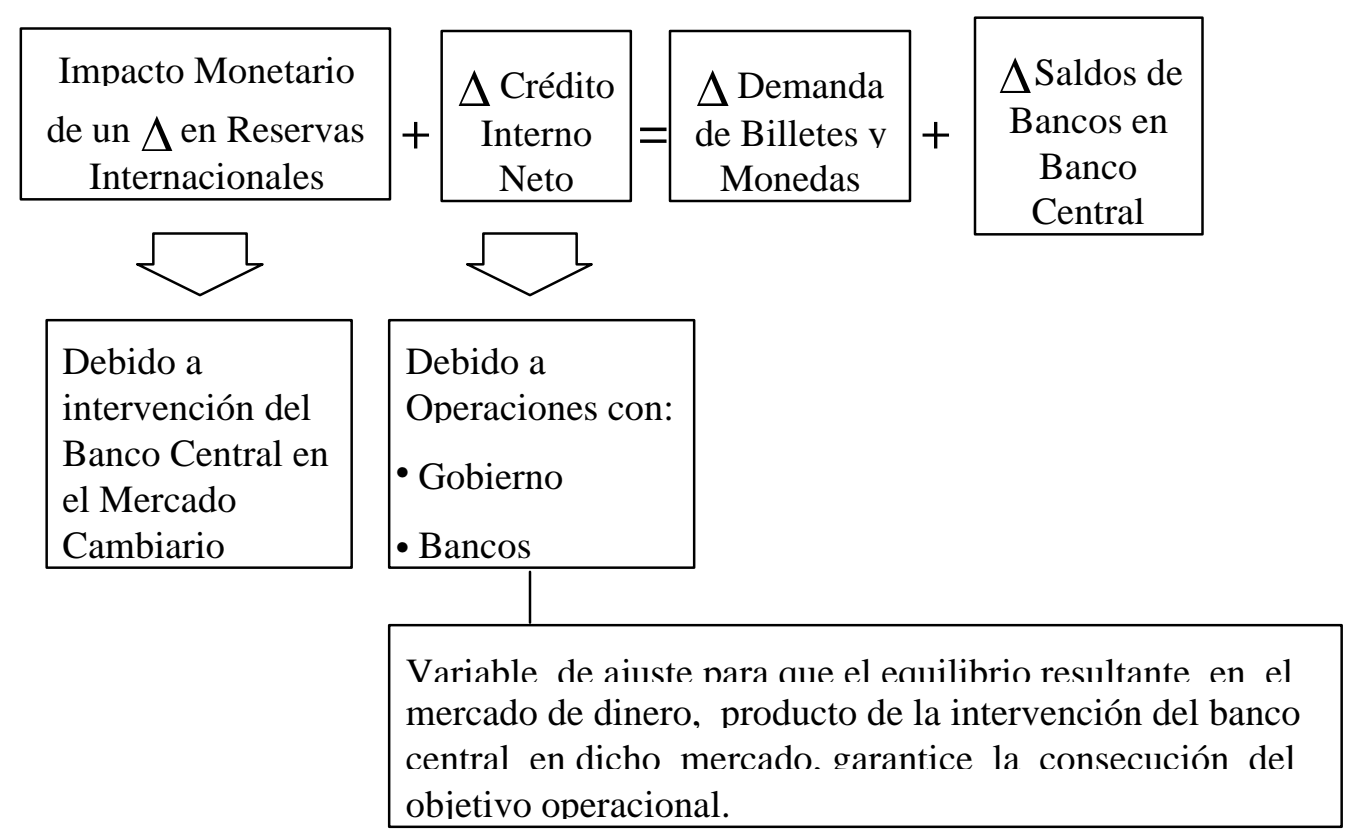

${ }^{12}$ Un nivel particular de las tasas de interés o cierta trayectoria de las reservas bancarias en el banco central. 
Una vez establecida la necesidad del banco central de intervenir en el mercado de dinero ya sea retirando o adicionando liquidez (afectando su crédito interno neto), esta intervención puede darse a través de transacciones realizadas bajo la iniciativa del banco central (operaciones de mercado abierto) o mediante la utilización de ventanillas para el manejo de la liquidez (ventanillas), que se activan por iniciativa de los participantes del mercado. Cualquiera de estos mecanismos de intervención puede representar la fuente marginal de liquidez que equilibre el mercado de dinero en forma congruente con el alcance del objetivo operacional del banco central. Cabe señalar que las intervenciones por iniciativa de la autoridad monetaria han sido, por lo general, más utilizadas que las ventanillas.

La utilización de las ventanillas a iniciativa de los bancos comerciales en muchos casos ha tomado la forma de "válvula de escape", que le permite a los participantes del mercado con faltantes de liquidez cubrir sus deficiencias en situaciones de urgencia. Inclusive, en ocasiones, la determinación de las condiciones que permiten el acceso a dicha fuente de liquidez, buscan limitar las fluctuaciones bruscas en la tasa de fondeo y enviar señales de política a los participantes del mercado.

Los principales instrumentos que han sido utilizados por los bancos centrales para el manejo de la liquidez son los requerimientos de reserva (que pueden incluir alguna modalidad que permita promediar saldos en el banco central), las operaciones de mercado abierto, las operaciones de swap con moneda extranjera y las ventanillas para el manejo de la liquidez. En algunos casos, también se ha utilizado la transferencia de depósitos del gobierno entre el banco central y las instituciones de crédito. Si bien algunos de estos instrumentos se encuentran estrechamente relacionados, éstos serán analizados por separado con el objeto de facilitar su comprensión. El cuadro 4 presenta los principales instrumentos utilizados por los bancos centrales para el manejo de la liquidez.

\section{Cuadro 4}

\section{Principales Instrumentos para el Manejo de la Liquidez}

1. Requerimientos de Reserva (incluye modalidad de promedios)

2. Operaciones de Mercado Abierto

a) Operaciones de Reporto con valores denominados en moneda nacional (compra/ venta).

b) Compra/ Venta D efinitiva de valores denominados en moneda nacional.

c) Créditos o D epósitos en el Banco Central.

3. O peraciones de Swap con Moneda Extranjera

4. Ventanillas para el Manejo de Liquidez

5. Transferencia de D epósitos del G obierno entre el banco central y la banca comercial 


\section{III.I. Requerimientos de Reserva}

Los requerimientos de reserva, entendidos éstos como la exigencia de la autoridad monetaria a que las instituciones de crédito mantengan cierto porcentaje de su captación en la forma de depósitos en el banco central, fueron en el pasado el instrumento más utilizado por los bancos centrales con el objeto de regular la liquidez en el mercado de dinero. Se argumentaba que dicho instrumento era crucial para determinar el tamaño del multiplicador bancario y la expansión del crédito ${ }^{13}$. No obstante, en fechas recientes se ha observado una marcada disminución en la utilización de este instrumento. Más aún, un número importante de bancos centrales mantiene en la actualidad requerimientos de reserva de tamaño insuficiente para afectar la expansión del crédito bancario, y en algunos casos inclusive, dichos requerimientos han sido abandonados por completo. El cuadro 5 muestra la cada vez menor utilización de los requerimientos de reserva por parte de los bancos centrales.

${ }^{13}$ Goodhart (1995) cuestiona esta visión tradicional sobre la existencia del multiplicador bancario y de la efectividad de los requerimientos de reserva para controlar la expansión del crédito. 


\section{Cuadro 5}

\section{Requenimientos de Reserva en Varios Países}

(en porcentaje)

\begin{tabular}{|c|c|c|c|}
\hline & 1989 & 1992 & 1997 \\
\hline \multicolumn{4}{|c|}{ Depósitos a la Vista } \\
\hline Alemania & 12.1 & 12.1 & 2.0 \\
\hline Australia & 1.0 & 1.0 & $1.0^{\mathrm{g}}$ \\
\hline Bélgica & 0.0 & 0.0 & 0.0 \\
\hline Canadá & 10.0 & $0.0^{c}$ & 0.0 \\
\hline Estados Unidos & 12.0 & $10.0^{d}$ & 10.0 \\
\hline Francia & $5.5^{\mathrm{a}}$ & $1.0^{\mathrm{e}}$ & $1.0^{\mathrm{g}}$ \\
\hline Inglaterra & 0.45 & 0.35 & 0.25 \\
\hline Japón & 1.75 & 1.2 & 1.2 \\
\hline México & $30.0^{b}$ & 0.0 & $0.0^{f}$ \\
\hline Nueva Z elandia & 0.0 & 0.0 & 0.0 \\
\hline Suecia & 0.0 & 0.0 & 0.0 \\
\hline \multicolumn{4}{|c|}{ Depósitos a Plazo } \\
\hline Alemania & 4.95 & 4.95 & 1.5 \\
\hline Australia & 1.0 & 1.0 & $1.0^{\mathrm{g}}$ \\
\hline Bélgica & 0.0 & 0.0 & 0.0 \\
\hline Canadá & 3.0 & $0.0^{c}$ & 0.0 \\
\hline Estados Unidos & 3.0 & 0.0 & 0.0 \\
\hline Francia & 3.0 & 0.0 & $0.0^{\mathrm{g}}$ \\
\hline Inglaterra & 0.45 & 0.35 & 0.25 \\
\hline Japón & 2.5 & 1.3 & 1.3 \\
\hline México & $30.0^{b}$ & 0.0 & $0.0^{f}$ \\
\hline Nueva Zelandia & 0.0 & 0.0 & 0.0 \\
\hline Suecia & 0.0 & 0.0 & 0.0 \\
\hline
\end{tabular}

a Válido desde el 16 de octubre de 1989.

b En 1989 se establece un coeficiente de liquidez de 30\% en lugar del encaje legal. En 1991 se elimina el coeficiente de liquidez.

c A partir de junio de 1992 el requerimiento de reserva marginal es de cero. Para julio de 1994 se habían eliminado todos los requerimientos de reserva.

d Válido desde el 2 de abril de 1992.

e Válido desde el 16 de mayo de 1992.

f A partir de marzo de 1995, se adopta un esquema de "encaje promedio cero".

g D atos para 1996.

Nota: Las cifras corresponden a los niveles más altos de reservas marginales.

Fuentes: Banco de Japón, Sistema de la Reserva Federal, Banco Central de Alemania, Banco de Francia, Banco de Canadá, Banco de Inglaterra, Banco de la Reserva de Nueva Zelandia, Banco de México, Borio (1997) y Sellon y Weiner (1996). 
Como se puede observar en el cuadro 5, durante los últimos años los niveles de los requerimientos de reserva de los bancos centrales han disminuido de manera importante. Tal es el caso de Alemania, E.U.A., Francia y Japón. Por su parte, Bélgica, Canadá, México, Nueva Zelandia y Suecia los han eliminado por completo. Inglaterra y Australia siguen manteniendo un pequeño nivel de requerimientos de reserva, aunque tan solo con el objeto de proveer ingresos para el banco central ${ }^{14}$.

La experiencia de México en la utilización de requerimientos de reserva es amplia. El encaje legal fue utilizado por primera vez en $1924^{15}$. A partir de esa fecha, el requerimiento de encaje se utilizó para distintos fines. En un principio, el encaje tuvo como propósito principal la protección de los depósitos del público en los bancos. Posteriormente, el encaje legal comenzó a utilizarse como instrumento de política monetaria, limitando la expansión crediticia de las instituciones bancarias, y también como vehículo para el financiamiento del gobierno y de sectores considerados como prioritarios para el desarrollo económico ${ }^{16}$.

La escasez de crédito en los sectores no considerados como prioritarios para el desarrollo económico de México, aunada al proceso inflacionario y al mantenimiento de tasas de interés artificialmente bajas, propiciaron la expansión de los mercados informales de crédito, los cuales, al no estar sujetos a las regulaciones de la banca tradicional, ganaban terreno en el otorgamiento de los créditos. El desarrollo de dichos mercados alcanzó un auge a mediados de 1988. Ante esta situación, se hizo patente la necesidad de tomar medidas encaminadas hacia la liberalización financiera, cuya finalidad era crear un marco institucional que le permitiera a la banca recuperar su posición competitiva en el mercado financiero, y al banco central regular las operaciones del sistema eliminando al mercado informal. Así, en octubre de 1988 se autorizó a los bancos a que éstos pudiesen invertir libremente los recursos captados a través de las aceptaciones bancarias, con la única condición de mantener un coeficiente de liquidez del 30 por ciento, constituido por depósitos en el Banco de México y/ o en valores gubernamentales. En abril de 1989, esta última condición se extendió también a los recursos captados mediante los instrumentos bancarios tradicionales, dando así lugar a la eliminación de las disposiciones de encaje obligatorio y de las normas de crédito selectivo, a la vez que se liberalizaron las tasas de interés pasivas ${ }^{17}$.

En septiembre de 1991 el Banco de México resolvió suprimir el coeficiente de liquidez obligatorio aplicable a los pasivos bancarios denominados en pesos señalado con anterioridad. La eliminación del coeficiente de liquidez respondía a la continuación del proceso de desregulación iniciado años atrás. Más aún, al aumentar la captación de recursos de los bancos, la presencia del coeficiente de liquidez daba lugar a una demanda creciente de valores gubernamentales, en circunstancias en que, dada la evolución favorable de las finanzas públicas, la oferta de estos valores se venía reduciendo. Cabe

\footnotetext{
14 Borio (1997).

15 Quepons (1973).

16 O rtiz (1994).

17 Banco de México (1989).
} 
señalar, que la eliminación del coeficiente de liquidez no implicó un cambio importante en la forma de instrumentar la política monetaria, dado que dicho coeficiente, al estar constituido principalmente por la adquisición de valores gubernamentales, no restaba capacidad de crédito a las instituciones crediticias, y por consiguiente no era un instrumento diseñado para afectar las condiciones monetarias ${ }^{18}$. Así, por varios años, la instrumentación de la política monetaria ya recaía primordialmente en la intervención del banco central en el mercado de dinero a través de las operaciones de mercado abierto ${ }^{19}$.

Existen diversas razones por las cuales las autoridades monetarias de los diferentes países han disminuido el uso de los requerimientos de reserva. Entre estas razones destaca la identificación del requerimiento de reservas con un impuesto a la intermediación financiera realizada por los bancos. La incidencia de dicho impuesto es ambigua, ya que los bancos tratarán de que la carga del impuesto recaiga sobre sus clientes, por lo que buscarán disminuir las tasas pasivas y aumentar las activas. Es de esperarse que los pequeños ahorradores, así como los deudores que difícilmente tengan acceso a fuentes alternativas de financiamiento, sean los que tengan menores oportunidades de evadir la carga del impuesto. La eliminación del impuesto asociado al requerimiento de reservas y de las distorsiones que éste conlleva, es una de las razones por las cuales los bancos centrales han reducido de manera importante dichos requerimientos.

O tra justificación de la menor utilización de los requerimientos de reserva radica en el hecho de que un sinnúmero de instituciones financieras no bancarias, que compiten con las instituciones de crédito en el otorgamiento de diversos servicios, no se encuentran sujetas a la constitución de reservas en el banco central, lo cual redunda en una competencia inequitativa en contra de los bancos. Así, las autoridades monetarias han coincidido en que en un entorno en el que las diferencias entre los distintos intermediarios financieros son cada vez menores, la exigencia de requerimientos de reserva para las instituciones de crédito resulta difícil de justificar.

Por otra parte, se ha alcanzado un consenso de que la efectividad de los requerimientos de reserva como instrumento de política monetaria se ha visto aminorada por la innovación financiera. Sobre esto último cabe recordar que durante muchos años, las instituciones bancarias en E.U.A. buscaron evadir la constitución de requerimientos de reserva creando nuevos tipos de pasivos que no se encontraban sujetos al requerimiento. De esta manera, los bancos intentaban cambiar la composición de sus pasivos hacia instrumentos no sujetos al requerimiento de reservas, tales como los certificados de depósito, las cuentas en Eurodólares y la captación vía reportos ${ }^{20}$.

\footnotetext{
18 Banco de México (1991).

${ }^{19}$ Con el objeto de evitar que la posible enajenación de los valores con los que estaba constituido el coeficiente de liquidez causara desequilibrios en el mercado financiero, los bancos debieron invertir cierto porcentaje de su captación en Bonos de D esarrollo del Gobierno Federal emitidos a largo plazo.

20 Sellon y Weiner (1996).
} 
Más importante aún, la experiencia de Bélgica, Canadá, Inglaterra ${ }^{21}$, México, Nueva Zelandia y Suecia, confirma el hecho de que la ausencia de requerimientos de reserva no implica en absoluto la pérdida del control de la política monetaria, y que dicho instrumento no es indispensable para un adecuado manejo monetario. La sección $\mathrm{V}$ analiza en detalle este último argumento.

Si bien un número importante de países aún mantienen requerimientos de reserva, la utilización de este instrumento para controlar los agregados monetarios ha sido prácticamente abandonada. Así, los requerimientos de reserva han sido utilizados principalmente por su efecto estabilizador sobre los movimientos de las tasas de interés de corto plazo. Dicho efecto estabilizador se logra generalmente, estableciendo alguna modalidad que permita promediar durante ciertos períodos de tiempo, los saldos de las instituciones bancarias en el banco central ${ }^{22}$. De esta manera, los bancos centrales han establecido períodos de cómputo para dichos requerimientos de aproximadamente un $\mathrm{mes}^{23}$.

Si bien países como Canadá y México no cuentan con la exigencia de que las instituciones de crédito constituyan reservas en el instituto emisor, si utilizan la modalidad de promedios de los saldos de los bancos en el banco central. Esto último con el objeto de limitar la volatilidad de las tasas de interés. La modalidad de promedios de los saldos de la banca en el instituto central en ausencia de requerimientos de reserva tradicionales ha dado lugar al mecanismo denominado "encaje promedio cero" ${ }^{24}$.

Bajo el esquema de "encaje promedio cero", la autoridad monetaria exige a las instituciones de crédito que al final del período de cómputo, el saldo promedio diario de sus cuentas en el banco central sea de cero. Lo anterior implica que en caso de que al cierre del día, algún banco presente un sobregiro en su cuenta en el banco central, dicha institución de crédito deberá compensar, dentro del mismo período de cómputo, el referido saldo negativo, con un depósito en su cuenta en el banco central de por lo menos igual magnitud. En caso de que alguna institución crediticia presente un saldo promedio negativo en su cuenta en el banco central al término del período de cómputo, dicho banco se hace acreedor a una penalización por parte de la autoridad monetaria.

\footnotetext{
${ }^{21}$ La existencia de un reducido requerimiento de reserva del Banco de Inglaterra obedece a que dicho requerimiento provee ingresos al banco central. Las autoridades del Banco de Inglaterra han reconocido públicamente que los requerimientos de reserva no representan un instrumento de política monetaria.

22 Borio (1997) presenta una reseña de los países que utilizan los requerimientos de reserva con el propósito de aminorar las fluctuaciones de la tasa de fondeo.

${ }^{23}$ En E.U.A el período de cómputo es de dos semanas y en España de diez días.

${ }^{24}$ En México este esquema comenzó a operar en marzo de 1995. A partir de ese entonces, el referido esquema ha sufrido diversas modificaciones, entre las que destacan la coincidencia del período de medición para los distintos bancos, el cambio en la penalización a la banca en caso de presentar un saldo promedio negativo al final del período de medición, y el establecimiento de límites a los saldos diarios de la banca en sus cuentas en el banco central que computan en el esquema de "encaje promedio cero". Para una revisión detallada ver Banco de México (1996), Gil Díaz (1997) y O’D ogherty (1997).
} 


\section{III.II. Operaciones de Mercado Abierto}

Las operaciones de mercado abierto son en la actualidad el principal instrumento de política monetaria utilizado por los bancos centrales para afectar la liquidez del sistema. Como se mencionó con anterioridad, estas operaciones se realizan por iniciativa de la autoridad monetaria.

Cabe señalar que la eficiente instrumentación de las operaciones de mercado abierto requiere de la existencia de un mercado de dinero profundo y desarrollado. De no ser este el caso, las operaciones de mercado abierto del banco central pueden generar distorsiones en el funcionamiento de dicho mercado. La falta de desarrollo de los mercados de dinero de distintos países obligaron a los bancos centrales a recurrir a la utilización de instrumentos que no eran de mercado, tales como los requerimientos de reserva, para llevar a cabo sus acciones de política monetaria.

Existen diversas modalidades para llevar a cabo operaciones de mercado abierto. Entre éstas destacan la compra/ venta de valores denominados en moneda nacional mediante operaciones de reporto, la compra/ venta definitiva de valores y los créditos o depósitos en el banco central. La frecuencia de las operaciones de mercado abierto depende, entre otros factores, de la forma en la que las variaciones en la liquidez en el mercado de dinero, ocasionadas por la intervención del banco central en el mercado de cambios, por movimientos en la cuenta del gobierno en el banco central y por modificaciones en la demanda de billetes y monedas, afecten la volatilidad de las tasas de interés.

\section{III.II.a. Operaciones de Reporto con Valores Denominados en Moneda Nacional (Compra/ Venta)}

Las operaciones de reporto con valores denominados en moneda nacional se han convertido en el instrumento preferido por los bancos centrales. Estas operaciones consisten en que el banco central realiza la compra o venta de valores con el acuerdo de realizar la operación inversa en una fecha predeterminada.

La compra en reporto ${ }^{25}$ se realiza cuando el objetivo del banco central es inyectar liquidez temporalmente al sistema y es prácticamente equivalente a otorgarle un crédito a la contraparte, y recibir el valor en cuestión como colateral del préstamo. Por su parte, las ventas en reporto ${ }^{26}$ ocurren cuando la intención de la autoridad monetaria es retirar liquidez del mercado. Las operaciones de reporto las realizan los bancos centrales tanto con valores emitidos por el sector público, y en su caso, por la propia autoridad monetaria ${ }^{27}$.

250 simplemente operación de reporto.

26 También se conoce como operación de reporto inverso.

${ }^{27}$ En ocasiones, los bancos centrales tratan de establecer la fecha de vencimiento del reporto con base en sus proyecciones de fechas en las que exista una alta probabilidad de que por cuestiones del manejo monetario se tenga que realizar la operación inversa. De esta manera, el banco central realiza un menor número de transacciones en el mercado de dinero, o bien realiza operaciones por un monto menor. 


\section{III.II.b. Compra/ Venta Definitiva de Valores Denominados en Moneda Nacional}

A diferencia de las operaciones de reporto, la compra/ venta definitiva de valores no implica el compromiso de llevar a cabo la operación inversa con la contraparte de la operación. Es decir, la inyección/ contracción de liquidez se hace de manera definitiva. Las operaciones de reporto, por lo general, han sido preferidas por los bancos centrales sobre las operaciones definitivas debido a que las operaciones de reporto tienden a aumentar la liquidez del mercado del valor utilizado en el reporto, a que tienen tan sólo un impacto indirecto sobre el precio de los valores, y a que logran romper la relación entre el plazo a vencimiento del título objeto del reporto y el plazo a vencimiento de la transacción. Por otra parte, las operaciones de carácter definitivo pueden implicar cierta disminución en la liquidez de los compradores de los títulos. No obstante, en países en los que los mercados de valores son profundos, la compra/ venta definitiva de valores representa un mecanismo importante para la instrumentación de la política monetaria ${ }^{28}$. En todo caso, la decisión de llevar a cabo operaciones de reporto o de carácter definitivo por parte del banco central obedece al tipo de señal que la autoridad monetaria desee enviar al mercado y al impacto que se quiera tener sobre las tasas de fondeo.

\section{III.II.c. Créditos o Depósitos en el Banco Central}

Al igual que la compra en reporto o la compra definitiva de valores, los créditos del banco central se realizan en circunstancias en las que la autoridad monetaria desea proveer liquidez, mientras que los depósitos en el banco central son instrumentados para retirar liquidez del sistema. La mayoría de estos créditos son otorgados por el banco central con la exigencia de colateral, o bien por conducto de operaciones de redescuento de valores. Los depósitos en el banco central son por lo general remunerados. Cuando los créditos o depósitos en el banco central se llevan a cabo mediante subasta, este tipo de operaciones resulta similar a los reportos 29 .

\section{III.III. Operaciones de Swap con Moneda Extranjera}

O tro instrumento para afectar la liquidez del mercado son las operaciones de swap con moneda extranjera. Estas operaciones consisten en realizar compras temporales de moneda extranjera con el propósito de inyectar liquidez, o de llevar a cabo ventas temporales de divisas con el objeto de retirar liquidez. La operación de swap resulta análoga a la realizada mediante reportos con valores denominados en moneda nacional, diferenciándose en que la operación de swap con moneda extranjera se lleva a cabo en el mercado de cambios en lugar de realizarse en el mercado de dinero. Suiza es un país que

\footnotetext{
${ }^{28}$ Tal es el caso de Bélgica, E.U.A., Francia, Inglaterra, Italia y Japón.

${ }^{29}$ En ocasiones, los depósitos en el banco central han sido utilizados con el objeto de que la autoridad monetaria mantenga una posición acreedora con respecto al mercado de dinero (Banco de México, 1998 y Escrivá y Fagan, 1996).
} 
ha utilizado en forma recurrente este tipo de operaciones para afectar la liquidez del sistema ${ }^{30}$.

\section{III.IV. Ventanillas para el Manejo de Liquidez}

Como se mencionó con anterioridad, las operaciones de mercado abierto son en la actualidad el instrumento más común para manejar la liquidez e influir sobre las tasas de interés de corto plazo. No obstante, un número importante de bancos centrales complementa sus operaciones de mercado abierto mediante el establecimiento de ventanillas para el manejo de liquidez. A diferencia de las operaciones de mercado abierto que se realizan por iniciativa del banco central, el acceso a las ventanillas ocurre por iniciativa de los propios bancos comerciales.

En un número importante de países, estas ventanillas se han establecido de tal forma que la tasa de interés a la que los bancos comerciales pueden acceder a la liquidez proporcionada por el banco central, determina un techo a la tasa de fondeo, mientras que la tasa de interés a la que puedan depositar sus excedentes de efectivo en el banco central establece un piso a dicha tasa. De tal manera, que el piso y el techo a la tasas de interés de muy corto plazo forman un corredor de tasas de interés, dentro del cual la tasa de fondeo fluctúa ${ }^{31}$.

La utilidad práctica de las ventanillas para el manejo de la liquidez radica en que su presencia limita la volatilidad de la tasa de fondeo, ya que éstas representan la fuente marginal de liquidez para los bancos que enfrentan situaciones de escasa disponibilidad de efectivo para enfrentar faltantes en los requerimientos de reserva al final del periodo de cómputo o para cubrir deficiencias de liquidez al cierre de operaciones del día. Los faltantes de liquidez al cierre del día para un banco en particular pueden a su vez originarse por errores del banco central en el pronóstico de la liquidez del sistema para ese día y por ineficiencias en el mercado que impidan una adecuada distribución de la liquidez entre los bancos.

Cabe agregar, que modificaciones a las tasas de interés a las cuales los bancos pueden acceder a las ventanillas, permiten el envío de señales por parte de la autoridad monetaria sobre la postura de su política. Así, la combinación de operaciones discrecionales por parte del banco central en conjunción con las ventanillas para el manejo de liquidez, le permiten a las autoridades monetarias instrumentar su política de la mejor manera posible, combinando la intervención en el mercado de dinero con el envío de señales ${ }^{32}$.

Resulta importante destacar, que no sólo existen diferencias entre los bancos centrales en cuanto al establecimiento de corredores de tasas de interés ${ }^{33}$, 0 de techos para la tasa de

\footnotetext{
30 O tros países que en ocasiones también utilizan este instrumento son Alemania, Bélgica e Italia.

${ }^{31}$ Algunos bancos centrales han establecido solamente el piso o el techo a la tasa de fondeo.

${ }^{32}$ Ver sección IV.

33 Alemania, Australia, Austria, Bélgica, Canadá, Suecia y Suiza.
} 
fonde $0^{34}$, sino también en las condiciones de acceso a las ventanillas ${ }^{35}$. En algunos $\operatorname{casos}^{36} \mathrm{el}$ acceso a la liquidez proporcionada por las ventanillas puede inclusive obtenerse a tasas de interés por debajo de las del mercado, aunque dicha práctica puede significar la pérdida de reputación de la institución bancaria ${ }^{37}$.

\section{III.V. Transferencia de Depósitos del Gobiemo entre el Banco Central y la Banca Comencial}

El Banco de Canadá realiza ajustes diarios en la liquidez del mercado mediante transferencias de depósitos del gobierno entre el banco central y los bancos comerciales ${ }^{38}$. Es decir, al contar el Banco de Canadá con la posibilidad de decidir la localización de los depósitos del gobierno entre su cuenta en el banco central o en bancos comerciales, la autoridad monetaria afecta la liquidez del sistema realizando transferencias de los depósitos del gobierno entre estas cuentas. De tal manera que si se desea aumentar la liquidez del sistema, el banco central transfiere depósitos del gobierno a la banca comercial, y cuando se busca retirar liquidez se realiza la operación inversa. La asignación de los depósitos del gobierno entre los bancos comerciales responde a los resultados de subastas que se realizan dos veces al mes.

\section{Señales de Política Monetaria}

El envío de señales del banco central sobre su objetivo de política es un elemento esencial para alcanzar dicha meta, ya que las señales ayudan a orientar las expectativas inflacionarias de los agentes económicos. Si bien las señales acerca de la postura de la política monetaria del banco central no son por sí mismas un instrumento mediante el cual la autoridad monetaria afecte la liquidez de la economía, dichas señales, de resultar efectivas, pueden propiciar acciones por parte de los agentes económicos tales que generen movimientos en las tasas de interés equivalentes a los que se presentarían en caso de registrarse modificaciones en la liquidez del sistema financiero ${ }^{39}$. Por esto último, algunos autores concluyen que no resulta ser una exageración argumentar que parte fundamental de la instrumentación de la política monetaria radica más en la comunicación del banco central con el mercado acerca de sus intenciones, que en el propio manejo de la liquidez ${ }^{40}$.

Las señales sobre la postura de política monetaria pueden tomar diversas formas dependiendo de las intenciones del banco central, así como de su disponibilidad de

\footnotetext{
34 Francia, Inglaterra, Italia y Japón.

35 Exigencia de colateral y límites a este tipo de financiamiento.

36 E.U.A. y Holanda.

37 Borio (1997) presenta una amplia descripción de los diferentes arreglos existentes para el acceso a las ventanillas de liquidez de los distintos bancos centrales.

38 Suiza también ha utilizado este mecanismo.

${ }^{39}$ Esto posiblemente ocurre por el hecho de que los agentes económicos anticipen la instrumentación de ciertas políticas por parte de la autoridad monetaria.

40 Borio (1997).
} 
instrumentos. Las señales se pueden transmitir ya sea a través de modificaciones a las condiciones a las que la autoridad monetaria suministra o retira liquidez, dejando claramente especificados los niveles de tasas de interés a los cuales interviene en el mercado de dinero ${ }^{41}, 0$ por conducto de referencias explícitas sobre alguna variable que por lo general no puede ser controlada directamente por el banco central pero sobre la cual puede ejercer cierta influencia ${ }^{42}$ (alguna tasa de interés de corto plazo $0^{43} 0$ la trayectoria de las reservas bancarias en el banco central $^{44}$ ).

En los bancos centrales en los que existe un objetivo sobre el nivel de alguna tasa de interés de corto plazo, las señales sobre la postura de la política monetaria se transmiten principalmente por conducto de anuncios de diferentes niveles objetivo para dichas tasas, o bien, mediante la determinación de las tasas de interés a las cuales se permite el acceso a las ventanillas para el manejo de la liquidez. De esta manera, las ventanillas no sólo funcionan como fuente marginal de liquidez en circunstancias de relativa escasez, sino también como elemento clave para el envío de señales sobre la política monetaria. Así, si la intención del banco central es instrumentar una política más restrictiva, tan sólo bastaría con anunciar un aumento en la tasa de interés a la cual se le permite a las instituciones de crédito acceder al financiamiento del instituto emisor. De esta manera, el encarecimiento del financiamiento otorgado por el banco central desincentivará el acceso de las instituciones de crédito a dicho financiamiento, lo cual presionará a la alza a las tasas de interés de mercado.

Por su parte, si el banco central opera en un régimen de "encaje promedio cero", el anuncio de la restricción monetaria tomaría la forma de un objetivo de encaje promedio negativo. De tal forma que las instituciones crediticias, con el objeto de no incurrir en penalización alguna por presentar un saldo promedio negativo en sus cuentas en el banco central, lo cual implicaría haber recurrido al financiamiento del banco central a través de la facilidad de sobregiro, llevarán a cabo una política de captación de fondos más activa, presionando así al alza a las tasas de interés. La experiencia de México en esta materia confirma el hecho de que tan sólo el anuncio del banco central de tener un objetivo de "encaje promedio negativo" ${ }^{45}$, puede generar una reacción al alza en las tasas de interés de manera inmediata, aún cuando el faltante de liquidez involucrado sea insignificante ${ }^{46}$.

\section{El Mercado de Base Monetaria y la Instrumentación de la Política Monetaria sin Requenimientos de Reserva}

El atributo principal que distingue a un banco central de cualquier otro intermediario financiero es su facultad de controlar la emisión de la base monetaria ${ }^{47}$. Como se señaló

\footnotetext{
${ }^{41}$ Alemania, Austria, Bélgica, Holanda y Suecia.

42 Esta variable es conocida como el objetivo operacional del banco central.

${ }^{43}$ Australia, Canadá y E.U.A.

44 Suiza y México por ejemplo.

45 También llamado objetivo de saldos acumulados negativo.

${ }^{46}$ Aguilar y Juan-Ramón (1997) y G reenham (1997).

47 También llamada dinero de alto poder.
} 
con anterioridad, parte fundamental de la conducción de la política monetaria trata precisamente acerca del ritmo de expansión o contracción de la base monetaria, lo cual da lugar al mecanismo de transmisión de la política monetaria.

La base monetaria se compone de los billetes y monedas emitidos por el banco central y por los depósitos que mantienen los bancos en el instituto emisor. Al mantener las instituciones de crédito cuentas en el banco central, la expansión de la base ocurre cuando el banco central abona dichas cuentas como resultado de transacciones tales como el otorgamiento de crédito o la adquisición de divisas. De manera inversa, la base monetaria se contrae cuando las transacciones entre la banca y el banco central implican la realización de cargos en las cuentas de las instituciones de crédito en el instituto central.

Las cuentas de los bancos en el banco central no sólo se utilizan para liquidar transacciones entre la autoridad monetaria y las instituciones crediticias, sino que también sirven para liquidar los resultados de las cámaras de compensación de documentos y de pagos electrónicos. Más aún, un número importante de operaciones interbancarias que se realizan en los mercados de dinero y capitales son liquidadas a través de estas cuentas. Cabe señalar, que la disposición de los bancos para demandar reservas en dichas cuentas y la forma en la que se lleve a cabo la liquidación de las operaciones referidas en las cuentas de la banca en el banco central, obedece a las características de los sistemas de pagos vigentes ${ }^{48}$.

En países en los que existen requerimientos de reserva, los saldos de las cuentas bancarias en el banco central dependen fundamentalmente de la exigencia de dicho requerimiento. En este escenario, las características del sistema de pagos juegan a lo mucho, un papel relativamente modesto en la determinación de la demanda por reservas de la banca en el banco central, por lo que la operatividad y funcionamiento de los arreglos de pagos guardan poca relación con la instrumentación de la política monetaria y por consiguiente con la determinación de las tasas de interés de corto plazo.

No obstante, sin la exigencia de los requerimientos de reserva la demanda de la banca por saldos en el banco central, inclusive por períodos de tiempo relativamente cortos, depende fundamentalmente de las características de los mecanismos de liquidación de los sistemas de pagos, de la posibilidad y del costo de incurrir en sobregiros en las cuentas de los bancos en el banco central, y de la frecuencia de las intervenciones del banco central en el mercado de dinero. Las características de los arreglos de pagos vigentes determinarán no sólo el monto de los saldos de la banca en el banco central, sino también la duración de dichos depósitos.

\footnotetext{
${ }^{48}$ Para el caso de México la liquidación de las transacciones señaladas en las cuentas de los bancos en el banco central puede realizarse sin la necesidad de que existan saldos positivos en el agregado de dichas cuentas.
} 
Por ejemplo en México, bajo el mecanismo de "encaje promedio cero" descrito con anterioridad, los depósitos de la banca en el Banco de México al cierre de operaciones sólo se realizan con el objeto de compensar sobregiros que hayan sido incurridos en días anteriores. Esto último lo realizan las instituciones de crédito con la finalidad de evitar hacerse acreedoras a la penalización del banco central por incurrir en un saldo promedio negativo en su cuenta al término del período de cómputo. No obstante lo anterior, las instituciones de crédito demandan saldos en sus cuentas en el banco central durante el día, inclusive por tan sólo algunos instantes, con el objeto de enfrentar sus compromisos de pago. Una vez enfrentados dichos compromisos, la demanda por depósitos en el banco central será de cero ${ }^{49}$.

Una característica de los arreglos de pagos a través de los cuales se afectan las cuentas de la banca en el banco central que tiene relevancia en la determinación de la demanda de reservas bancarias en el banco central ${ }^{50}$, es si éstos operan bajo la modalidad de saldos brutos o netos. De manera general, la modalidad de saldos brutos se refiere a que solamente pueden realizarse cargos a las cuentas de la banca en el banco central, cuando dichas cuentas cuentan con depósitos de por lo menos igual magnitud. Dicho de otra forma, el esquema de saldos brutos no permite la posibilidad de que algún banco comercial incurra en sobregiros con el banco central. Por su parte, en la modalidad de saldos netos, los bancos centrales realizan uno 0 varios "neteos" entre los distintos cargos y abonos que se vayan presentando en las cuentas de los bancos en el banco central durante el día. Con base en este último esquema, la realización de cierto pago por parte de un banco a través de su cuenta en el banco central, no necesariamente requiere que dicho banco cuente en ese preciso momento con un depósito en su cuenta en el instituto central ${ }^{51}$. De acuerdo a la descripción de los esquemas de pago brutos o netos, sería de esperarse que bajo la modalidad de saldos brutos la banca demande un mayor monto de reservas en el banco central, que bajo el esquema de saldos netos ${ }^{52}$.

Como se desprende de lo anterior, en caso de que no existan requerimientos de reserva, la demanda por reservas bancarias en el banco central, ya sea al cierre de operaciones o durante el día, no guarda relación alguna con la demanda del público por depósitos a la vista o a plazo, tal como sucedería en el caso de existir requerimientos de reserva ${ }^{53}$, sino que mantiene una relación más estrecha con las necesidades de los bancos de enfrentar pagos con el instituto emisor o con otros intermediarios financieros. Cabe señalar, que la demanda por liquidez de las instituciones de crédito con el objeto de enfrentar sus compromisos de pago, no necesariamente debe quedar correspondida por una demanda

\footnotetext{
${ }^{49}$ A menos que el banco en cuestión busque compensar un sobregiro previo.

${ }^{50}$ Inclusive en la determinación de la demanda por reservas intradía.

${ }^{51}$ Con el objeto de limitar el riesgo crediticio al que se enfrentan los bancos centrales al operar bajo un esquema de saldos netos, las autoridades monetarias de distintos países han establecido diversas medidas entre las que destacan el establecimiento de límites a los sobregiros de la banca comercial en sus cuentas en el banco central, la obligación de mantener colateral que respalde dichos sobregiros, y mecanismos de compartición de pérdidas entre los distintos participantes del sistema de pagos.

${ }^{52}$ Johnson (1998) y Summers (1994) presentan una detallada descripción de los distintos arreglos de pagos.

${ }^{53}$ Asumiendo que el requisito de encaje varía de acuerdo al tipo de pasivo.
} 
de reservas bancarias en el banco central. Dicha demanda por liquidez puede tan sólo manifestarse durante un breve lapso en el mercado de dinero.

A manera de ejemplo ${ }^{54}$, mientras mayores sean los cargos por sobregiro ${ }^{55}$, y mayor sea el grado de incertidumbre del flujo de pagos que enfrenten las instituciones de crédito, mayor será la demanda por reservas bancarias en el banco central en un momento determinado. De igual manera, si el banco central establece alguna modalidad que le permita a los bancos promediar sus saldos en el banco central durante cierto período de tiempo, la demanda por reservas bancarias en el banco central se ajustará con base en dicha facilidad. Por su parte, sería de esperarse que en países en los que el banco central interviene esporádicamente en el mercado de dinero, los bancos comerciales demanden un mayor monto de reservas bancarias en el banco central para enfrentar sus compromisos de pago ${ }^{56}$, que en el caso de países en los que los bancos centrales intervienen constantemente en el mercado ${ }^{57}$.

Cabe aclarar que el elemento crucial de esta discusión radica en que aún en la ausencia de requerimientos de reserva, seguirá existiendo una demanda de liquidez por parte de la banca. Como se mencionó con anterioridad, dicha demanda puede inclusive manifestarse tan sólo durante algunos instantes del día con el objeto de que los bancos enfrenten sus compromisos de pago. Precisamente, será a través de su influencia sobre esta demanda y del manejo de la oferta de liquidez, la manera en la que el banco central afecte las tasas de interés de corto plazo e instrumente la política monetaria que juzgue adecuada.

Por otra parte, los bancos también demandan billetes y monedas ${ }^{58}$ para poder enfrentar la demanda del público por este agregado monetario. La demanda de billetes y monedas por parte del público responde fundamentalmente al costo de oportunidad de mantener este agregado monetario, del ritmo de la actividad económica, de la existencia de medios de pagos alternativos y de los precios. D ebido a que el público acude a las instituciones bancarias con el objeto de satisfacer su demanda por liquidez, los requerimientos de efectivo por parte del público representan a su vez la demanda de billetes y monedas de los bancos. En términos generales, los bancos centrales satisfacen la demanda de billetes y monedas pasivamente, por lo que la estrategia de la política monetaria se relaciona más estrechamente con la afectación de los saldos de las cuentas de los bancos en el banco central que con el proceso mediante el cual se satisface la demanda por billetes y monedas.

\footnotetext{
${ }^{54}$ Asumiendo que la demanda por liquidez de la banca queda correspondida por una demanda por reservas bancarias en el banco central, aunque dicha demanda prevalezca tan sólo por algunos instantes.

${ }^{55} \mathrm{Al}$ cierre de operaciones o diurnos.

56 En E.U.A. y Holanda, el banco central interviene en el mercado de dinero tan sólo algunas veces durante la semana, mientras que en Alemania, el banco central interviene en forma muy esporádica.

${ }^{57}$ El Banco de Inglaterra llega a intervenir en el mercado de dinero hasta tres veces al día. En Australia, Canadá, Bélgica y México, la autoridad monetaria interviene generalmente una vez al día.

58 El otro elemento de la base monetaria.
} 
Por su parte, como se mencionó anteriormente, la oferta de base monetaria, la cual repercute de manera directa sobre los saldos de las cuentas de las instituciones de crédito en el instituto emisor, se afecta tanto por la intervención del banco central en el mercado de cambios como en el mercado de dinero. El que la autoridad monetaria cuente con información anticipada de las variaciones en la oferta como en la demanda por liquidez, le permite determinar el monto de su intervención en el mercado de dinero, de tal forma que la liquidez resultante sea la deseada por el instituto central.

El mercado de base monetaria es un mercado especial. En este mercado el banco central juega un papel preponderante, pues dicha institución no sólo representa la única fuente de liquidez, sino que además, mediante la forma en que realiza su intervención en el mercado de dinero y los lineamientos que definen la operación de los sistemas de pagos, el instituto emisor logra influir de manera directa el comportamiento de la demanda. Así, el principal reto que enfrentan las autoridades monetarias consiste precisamente en regular la oferta de base monetaria y en establecer reglas y lineamientos de operación que afecten la demanda por base, de tal forma que la instrumentación de la política monetaria resultante garantice el cumplimiento de su objetivo final.

En la mayoría de los países la demanda por liquidez para hacer frente a compromisos de pago es el factor relevante que afecta la demanda por reservas en el banco central ${ }^{59}$, inclusive tan sólo por algunos instantes. Esto último ocurre ya sea porque en algunos de estos países no existen requerimientos de reserva, o bien, debido a que no se permite utilizar los saldos correspondientes a estos requerimientos para enfrentar faltantes de liquidez al final del día ${ }^{60}$.

Con base en el análisis anterior, puede concluirse que existe un número de factores que determinan la demanda por liquidez de las instituciones de crédito y la oferta de base monetaria. La interacción entre estas dos funciones en un momento en el tiempo, determina el nivel de la tasa de interés de corto plazo, lo cual representa el primer eslabón del mecanismo de transmisión de la política monetaria. Con el objeto de alcanzar un mejor entendimiento de la determinación de la tasa de interés de corto plazo, a continuación se presenta un análisis gráfico ${ }^{61}$ de los diferentes elementos que juegan un papel importante en la interacción entre la oferta y la demanda de liquidez. Para efectos del análisis se asumirá que la demanda por liquidez de las instituciones de crédito para enfrentar sus compromisos de pago, tendrá como contrapartida, aunque sea tan sólo por algunos instantes, un depósito de la banca en el banco central. Dicho de otra manera, se supondrá que la banca utiliza su cuenta en el banco central para hacer frente a sus obligaciones de pagos, por lo que la demanda por liquidez de la banca se manifestará a través de una demanda por reservas bancarias en el banco central.

\footnotetext{
59 Tal es el caso de Australia, Bélgica, Canadá, Holanda, Inglaterra y México.

${ }^{60}$ Australia y Holanda.

${ }^{61}$ Análisis similares se presentan en Borio (1997) y en Sellon y Weiner (1996 y 1997).
} 
La gráfica 1 muestra la demanda por reservas bancarias en el banco central (D). Esta demanda esta conformada por dos elementos: a) la demanda de reservas bancarias para satisfacer los requerimientos de reserva, la cual es función del coeficiente requerido de reservas y de la elección del público por mantener depósitos a la vista 0 a plazo en las instituciones de crédito $^{62} \mathrm{y}, \mathrm{b}$ ) la demanda por reservas para enfrentar contingencias de pagos ${ }^{63}$. La demanda se presenta con pendiente negativa debido a que a mayores tasas de interés, los depositantes retirarán sus recursos de cuentas a la vista y los transferirán a depósitos que ofrezcan mayor rendimiento, los cuales pueden estar exentos del requerimiento de reserva, o bien contar con un coeficiente menor. Esta acción por parte de la banca se reflejará en una menor cantidad demandada de reservas bancarias en el instituto central.

\section{Gráfica 1}

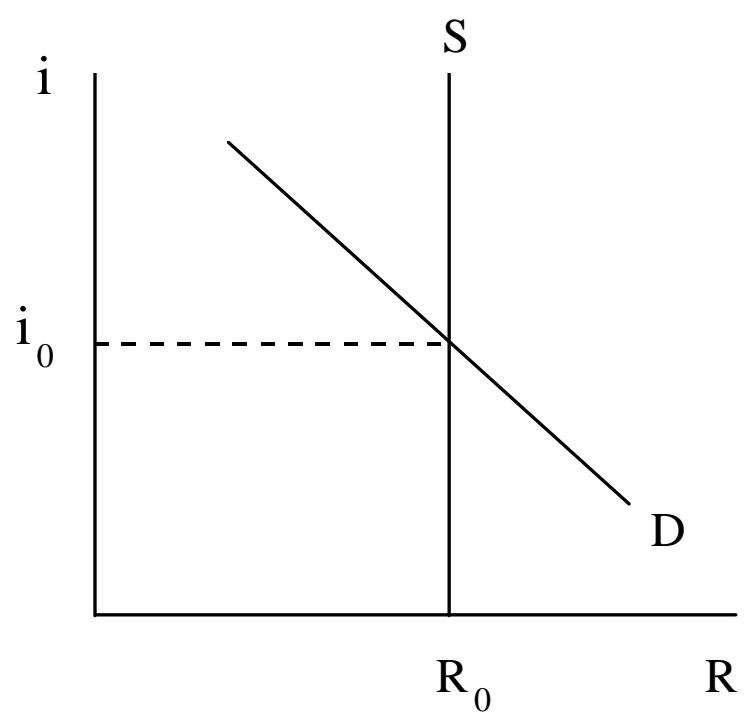

Por otra parte, aún en el caso de que no existan requerimientos de reserva, la demanda por reservas bancarias en el banco central, en este caso la de reservas para enfrentar compromisos de pago, mostrará una pendiente negativa. Si se considera que por lo general los depósitos bancarios en el banco central no son remunerados, las instituciones de crédito deben decidir entre incurrir en el costo de mantener saldos ociosos en el banco central, enfrentar el costo de presentar un sobregiro con el instituto emisor, o recurrir al financiamiento por parte de algún otro intermediario financiero en circunstancias de relativa iliquidez en el mercado. Así, conforme las tasas de interés aumenten, el costo de mantener saldos ociosos en el banco central aumentará, lo que inducirá a los bancos a mantener menores niveles de reservas

\footnotetext{
${ }^{62}$ Asumiendo que el requisito de encaje varía de acuerdo al tipo de pasivo.

63 Motivo precaución.
} 
La oferta de reservas (S) se dibuja en forma vertical, ya que ésta se determina por la intervención del banco central en el mercado de dinero 0 en el de cambios ${ }^{64}$. D e esta manera, la influencia que el banco central ejerza sobre la interacción entre estas dos curvas determinará el nivel de equilibrio de la tasa de interés de corto plazo (ver gráfica 2).

\section{Gráfica 2}

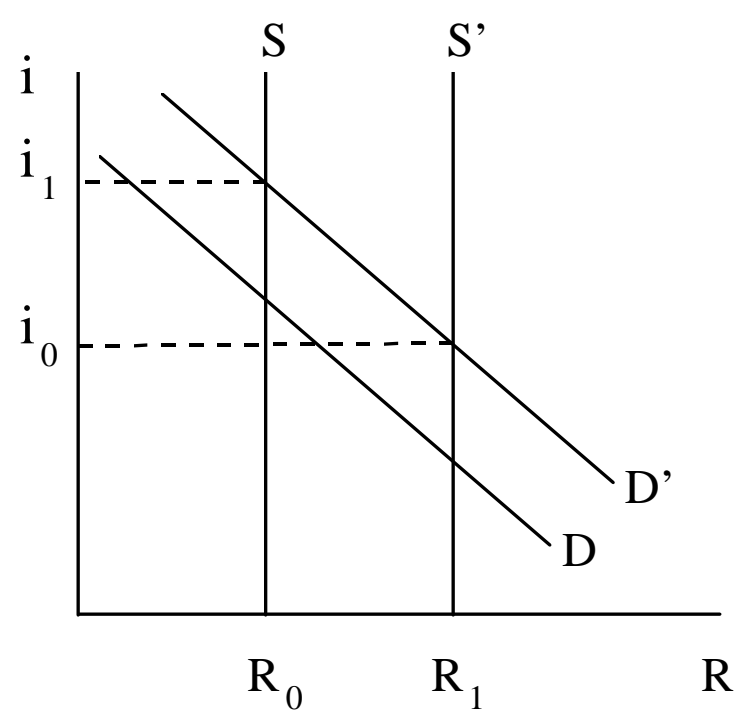

Por ejemplo, si ante un aumento en la demanda por reservas bancarias en el banco central $\left(D^{\prime}\right)$, la autoridad monetaria no desea que dicho aumento se refleje en mayores tasas de interés $\left(\mathrm{i}_{1}\right)$, el banco central deberá aumentar la oferta de base monetaria a $\left(\mathrm{S}^{\prime}\right)$. De manera similar, variaciones en la liquidez en el mercado de dinero pueden propiciar desplazamientos de la curva de oferta, con la consiguiente volatilidad sobre las tasas de interés. Así, la intervención del banco central en el mercado de dinero debe considerar dichas adiciones o reducciones de liquidez, con el objeto de que el desplazamiento de la curva de oferta determine las condiciones monetarias requeridas por el instituto central.

Podría existir la preocupación de que la eliminación de requerimientos de reserva propicie una mayor volatilidad de las tasas de interés de corto plazo. Esta volatilidad puede a su vez transmitirse a tasas de interés de más largo plazo y así afectar la actividad económica. La mayor volatilidad de tasas de interés en ausencia de requerimientos de reserva podría surgir por la mayor dificultad de los bancos centrales para pronosticar la demanda por reservas bancarias en el instituto emisor, ya que en este caso la demanda por reservas dependerá de las características propias del sistema de pagos y de la incertidumbre del flujo de pagos que enfrenten los bancos.

${ }^{64}$ Como se verá más adelante, la introducción de ventanillas para el manejo de liquidez implicará que la oferta presente pendiente positiva o que sea horizontal. 
Más aún, puede darse el caso de que en ausencia de requerimientos de reserva, la demanda por reservas bancarias se vuelva más inelástica con respecto a cambios en la tasa de interés, lo cual a su vez resulte en mayor volatilidad de las tasas de interés de corto plazo. La menor elasticidad de la demanda en el caso de que se eliminen los requerimientos de reserva obedece al hecho de que en este caso la demanda de reservas para enfrentar alguna contingencia de pagos no anticipada seguramente será menor que en el caso en el que exista encaje. Ante este escenario, al enfrentar un faltante inesperado de liquidez, derivado por ejemplo por la intervención del banco central en el mercado de cambios, los bancos llevarán a cabo una política más agresiva para conseguir recursos financieros, por lo que la presión sobre la tasa de interés será mayor. La situación descrita se presenta en la gráfica 3, en donde, ante una reducción imprevista de la oferta, la inelasticidad de la demanda propicia mayores aumentos en la tasa de interés ( $\mathrm{i}_{2}$ en lugar de $\mathrm{i}_{1}$ ).

\section{Gráfica 3}

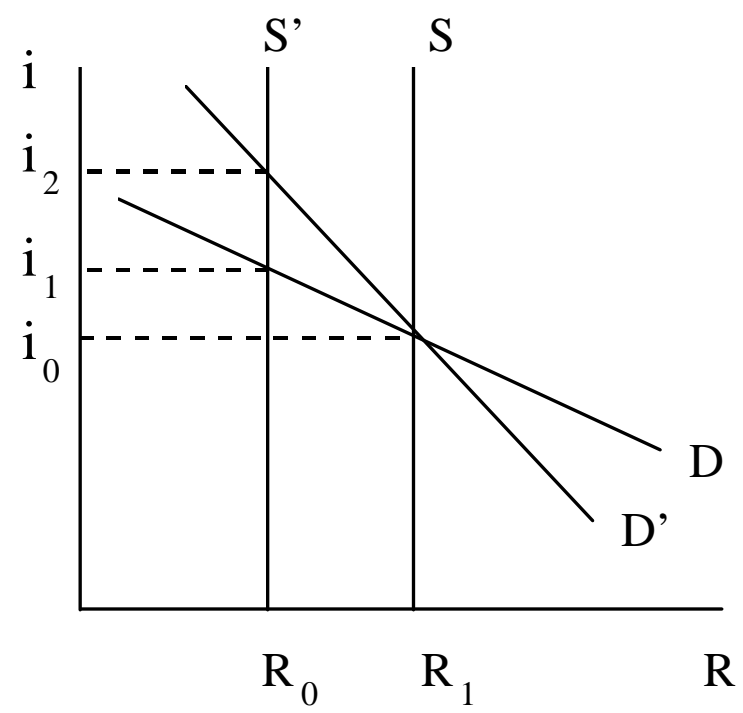

La volatilidad de las tasas de interés aparece cuando los bancos, al enfrentar una posición de liquidez distinta a la deseada, llevan a cabo acciones en el mercado de dinero con el objeto de cubrir deficiencias o eliminar excedentes de liquidez. En términos generales, la volatilidad de las tasas de interés de corto plazo dependerá del monto del faltante o del sobrante de liquidez del sistema, de la distribución de la liquidez entre los bancos, de la posibilidad de promediar saldos de la banca en el banco central y de los mecanismos institucionales que permitan suministrar o retirar liquidez del mercado al final del día. Así, por ejemplo, en un número de países, que en ausencia de requerimientos de reserva tradicionales, operan bajo un régimen de saldos diarios, en el que no se permite a las instituciones de crédito incurrir en sobregiros en sus cuentas en el banco central al cierre del día, los bancos satisfacen sus necesidades de liquidez accediendo a las ventanillas para 
el manejo de la liquidez y al mercado de "nivelación de fondos prestables." ${ }^{\prime 65} \mathrm{Tal}$ es el caso de Bélgica, Inglaterra, Nueva Z elandia y Suecia, entre otros.

Cabe añadir, que el tamaño del faltante o del sobrante de liquidez del sistema en un momento en particular, dependerá en gran medida, de la habilidad del banco central para pronosticar las necesidades de liquidez de la banca y de su facultad para actuar con prontitud en el mercado de dinero. Por ejemplo, si el banco central subestima la demanda por reservas bancarias, éste ofrecerá un monto de base monetaria que resulte menor al requerido por el mercado. Conforme las instituciones de crédito busquen obtener la liquidez necesaria, las tasas de interés se ajustarán al alza.

Como se mencionó con anterioridad, una manera de reducir la volatilidad de las tasas de interés es introduciendo alguna modalidad que permita compensar o promediar saldos en el banco central durante un período de tiempo dado, sin que esto implique la existencia de requerimientos de reserva positivos ${ }^{66}$. La modalidad de promedios puede reducir la volatilidad señalada al permitirle a las instituciones de crédito compensar un faltante 0 eliminar un sobrante de liquidez a lo largo del tiempo ${ }^{67}$. Dicho de otra manera, no es la presencia del requerimiento de encaje positivo lo que permite reducir la volatilidad de las tasas de interés, sino la existencia de la modalidad de promedios que generalmente caracteriza a la exigencia de requerimientos de reserva positivos. Así, bajo un sistema en el que no existan requerimientos de reserva positivos, pero en el que se presente la posibilidad de promediar los saldos de la banca en el banco central, se podría reducir de manera importante la volatilidad de las tasas de fonde $0^{68}$.

No obstante, algunos autores han sugerido que la modalidad de promedios puede producir una indeterminación en la demanda de reservas bancarias en el banco central, lo cual puede dificultar la adecuada instrumentación de la política monetaria ${ }^{69}$. Dicha indeterminación de la demanda puede presentarse en situaciones en las que antes del período de cómputo del encaje, las instituciones de crédito, por el hecho de aún contar con cierto lapso para compensar faltantes o eliminar sobrantes de liquidez para cumplir con el requerimiento establecido en la modalidad de promedios, se comporten de manera errática en el mercado de dinero. Este comportamiento errático puede resultar difícil de predecir por parte del banco central y propiciar mayor volatilidad en las tasas de fondeo. Con el objeto de remediar esta situación, las autoridades monetarias han establecido políticas que desincentivan el comportamiento señalado por parte de los bancos en el mercado de dinero. Dichas políticas se refieren a la determinación de los costos de

\footnotetext{
65 Los mercados de "nivelación de fondos prestables" se refieren a la posibilidad de que los bancos comerciales intercambien fondos prestables antes del cierre del día, una vez que las instituciones de crédito conocen los resultados de las diferentes cámaras de compensación. En algunas ocasiones el banco central también participa en estos mercados suministrando o retirando liquidez (O’D ogherty 1997).

66 Tal es el caso de Canadá y México.

${ }^{67}$ La introducción de la modalidad de promedios permitiría reducir el grado de inelasticidad de la demanda de reservas bancarias en el banco central.

$68 \mathrm{Al}$ no existir requerimientos de reserva positivos, pero si alguna modalidad de promedios, se asume implícitamente que el banco central permitirá la aparición de sobregiros de la banca en el instituto central.

69 Pérez Porrúa (1997).
} 
incurrir en sobregiros en las cuentas de los bancos en el banco central, así como el establecimiento de límites a dicho financiamiento ${ }^{70}$.

Cabe señalar que modificaciones en los parámetros de operación de las ventanillas para el manejo de la liquidez pueden alterar la elasticidad de la demanda o de la oferta de reservas bancarias en el banco central, lo que a su vez tendrá un impacto sobre la volatilidad de las tasas de interés de corto plazo. La curva (S) de la gráfica 4 presenta el caso en el que los bancos no pueden recurrir al financiamiento del banco central a través de las ventanillas para el manejo de la liquidez, por lo que al presentarse errores en el pronóstico de la demanda por reservas bancarias ( $D^{\prime}$ en lugar de $D$ ), la tasa de interés aumentará de $\mathrm{i}_{0} a \mathrm{i}_{2}$.

En el caso extremo de que el instituto central satisfaga la totalidad de las necesidades de liquidez a la tasa de interés $i_{0}$, (curva $\left(S^{\prime}\right)$ ), variaciones en la demanda de reservas bancarias no tendrían ningún efecto sobre las tasas de interés, por lo que la volatilidad de éstas se eliminaría por completo. La curva $\left(\mathrm{S}^{\prime \prime}\right)$ presenta el caso intermedio a los dos anteriores. Es decir, ante la presencia de restricciones al acceso de los bancos a las ventanillas del banco central para obtener financiamiento, o bien, en el caso de que la disponibilidad de recursos por parte de la autoridad monetaria a través de sus ventanillas aumente conforme la tasa de fondeo también se incremente, la oferta tendrá pendiente positiva, por lo que variaciones en la demanda por reservas bancarias tendrán un efecto más moderado sobre las tasas de interés que en el caso de que no exista esta facilidad de préstamo para los bancos (la tasa de fondeo aumenta de $\mathrm{i}_{0}$ a $\mathrm{i}_{1}$ ).

\section{Gráfica 4}

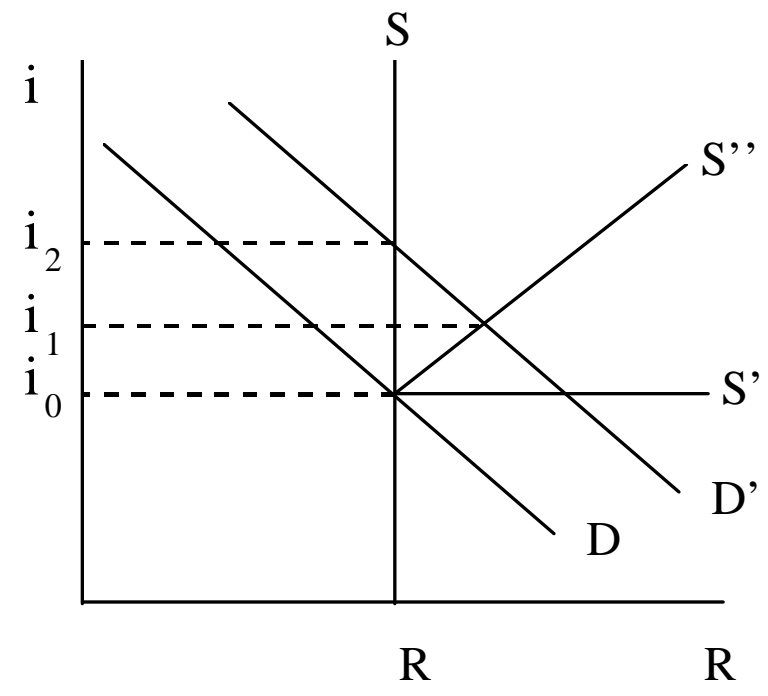

70 Ver Clinton (1997) para el caso de Canadá, y O ’D ogherty (1997) para el caso de México. 
Con base en el análisis gráfico presentado, queda claro que la tasa de interés de corto plazo y las condiciones monetarias en el mercado de dinero, dependen de manera crucial de los factores que determinan la demanda por reservas bancarias en el banco central en un momento dado y de la oferta de base monetaria.

El establecimiento de mecanismos tales como la modalidad de promediar saldos de la banca en el banco central o el acceso de las instituciones de crédito a ventanillas para el manejo de liquidez, permiten disminuir la volatilidad de la tasa de interés de corto plazo, al afectar la elasticidad de las funciones señaladas. Así, la conjunción de políticas de la autoridad monetaria con el objeto de influir sobre la interacción de las curvas de oferta y de demanda, y la capacidad del banco central para compensar de manera oportuna movimientos erráticos en dichas curvas, constituyen un elemento esencial para la adecuada instrumentación de la política monetaria. El control monetario del banco central en el mercado de dinero da lugar a que la primera etapa del mecanismo de transmisión de la política monetaria ocurra de manera ordenada.

\section{Consideraciones Finales}

Este trabajo analiza la manera en la que un número de países ha venido instrumentando su política monetaria. Parte importante del análisis se centra en la cada vez menor utilización de los requerimientos de reserva como instrumento para afectar las condiciones monetarias de la economía y los retos que dicha medida impone a los bancos centrales. En específico, el trabajo argumenta que la conjunción de medidas del banco central orientadas a influir sobre las condiciones monetarias en el mercado de dinero y su capacidad de compensar de manera oportuna movimientos erráticos de las curvas de demanda y de oferta de base monetaria, constituyen un elemento esencial para la adecuada instrumentación de la política monetaria. La evidencia empírica de varios países, incluyendo a México, indica que el hecho de que el banco central logre garantizar la existencia, en un momento dado, de una demanda por liquidez de la banca, que le permita a las instituciones de crédito hacer frente a sus compromisos de pago, resulta fundamental para un adecuado manejo monetario.

La cada vez menor utilización de los requerimientos de reserva como instrumento de política monetaria obedece, entre otros factores, al reconocimiento de que su efectividad para afectar las condiciones monetarias se ha visto disminuida. No obstante, algunos países que los han eliminado, han conservado la modalidad que permite promediar los saldos de la banca en el instituto central. Esto debido a que dicha modalidad puede disminuir la volatilidad de las tasas de interés de corto plazo y en algunos casos, facilitar el envío de señales sobre la postura de la política monetaria.

Cabe agregar, que la volatilidad de las tasas de interés de corto plazo también dependerá, entre otros factores, de las provisiones existentes que permitan suministrar o retirar liquidez del mercado en un momento determinado. Así, en diversos países, que en ausencia de requerimientos de reserva tradicionales operan bajo un régimen de saldos diarios, en el que no se permite que las instituciones de crédito incurran en sobregiros en 
sus cuentas en el banco central al cierre del día, existen mecanismos tales como las ventanillas para el manejo de la liquidez y los mercados de "nivelación de fondos prestables", que permiten satisfacer los faltantes de liquidez, de tal manera que las tasas de interés no presenten movimientos erráticos.

La ausencia de requerimientos de reserva no implica la desaparición de la demanda por liquidez de las instituciones de crédito, sino que dicha demanda será distinta a la que se presentaría en el caso de existir la exigencia de mantener depósitos en el banco central. En ausencia de requerimientos de reserva, la demanda por liquidez de la banca puede quedar correspondida por una demanda de reservas bancarias en el banco central por un cierto período de tiempo, el cual inclusive podría ser de tan sólo unos instantes, o bien manifestarse como una demanda por liquidez en el mercado de dinero sin tener como contrapartida una demanda por reservas en el banco central. La eliminación de los requerimientos de reserva tradicionales implica que la demanda por liquidez señalada se determine por factores tales como las características de los mecanismos de liquidación de los sistemas de pagos y de la posibilidad y del costo de incurrir en sobregiros en las cuentas de los bancos en el banco central, entre otros factores. Precisamente, es a través de la influencia de la autoridad monetaria sobre dicha demanda y del manejo de la oferta de liquidez, la forma en la que el banco central afecta las condiciones monetarias de la economía y da lugar al inicio del mecanismo de transmisión de la política monetaria. El análisis y comprensión de estas consideraciones ha sido el objetivo del presente trabajo. 


\section{Referencias}

Aguilar, A. y V. H. Juan-Ramón (1997), "D eterminantes de las Tasas de Interés de Corto Plazo en México: Efecto de las Señales del Banco Central", en La Pdítica Mondaria en México, Suplemento Gaceta de Economía, Instituto Tecnológico Autónomo de México, Año 3, Número 5.

Aspetsberger, A. (1996), "Open Market Operations in EU Countries", Staff Paper, № 3, European Monetary Institute.

Banco de México (1989), InfomeAnual, México, D .F.

Banco de México (1991), InfomeAnual, México, D.F.

Banco de México (1996), InformeAnual, México, D .F.

Banco de México (1998), InfomeSdbrela Pdítica Montania México, D.F.

Bank for International Settlements (1997), Implementation and Tadics of Mondary Pdigy, Conference Papers Vol. 3., Basle.

Bernanke, B. and F. S. Mishkin (1992), "Central Bank Behavior and the Strategy of Monetary Policy: O bservations from Six Industrialized Countries", Macroeconomiss Annul, NBER.

Bisignano, J. (1996), " Varieties of Monetary Policy Operating Procedures: Balancing Monetary O bjectives with Market Efficiency", Working Paper № 35, Bank for International Settlements, July.

Borio, C. E. V. (1997), "Monetary Policy Operating Procedures in Industrial Countries", en Bank for International Settlements, Implementation and Tatics of Montary Pdig, , Conference Papers Vol. 3., Basle.

Clinton, K. (1997), "Implementation of Monetary Policy in a Regime with Zero Reserve Requirements", WorkingPaper 97-8, Bank of Canada.

Copelman, M. and A. M. Werner (1996), "Exchange Rate Policy and the Bank Lending Channel: Sectoral Evidence from Mexico", Working Paper Series, Federal Reserve Board, Washington, D.C.

Duguay, P. (1994), "Empirical Evidence on the Strength of the Monetary Transmission Mechanism in Canada: An Aggregate Approach", Jaumal of Mondary Economics February.

Ericsson, N. R. and N. A. Kerbeshian (1997), "Monetary Conditions Indexes: A Bibliography with Synopses of Articles", manuscrito no publicado.

Escrivá, J. L. and G. P. Fagan (1996), "Empirical Assessment of Monetary Policy Instruments and Procedures (MPIP) in EU Countries", Staff Paper №2, May, European Monetary Institute. 
European Monetary Institute (1997), The Singe Montary Pdigy in Stage Three Geneal Doumentation on ESCB MondaryPdigy Instruments and Procedures September.

European Monetary Institute (1997), Speeification of theOperational Framenork, January.

Freedman, C. (1994), "The Use of Indicators and of the Monetary Conditions Index in Canada", en Baliño, T. J. T and C. Cottarelli, Framenorks for Mondary Stability, IMF, Washington, D.C.

Gil Díaz, F. (1997), "La Política Monetaria y sus Canales de Transmisión en México", en La Pdítica Mondania en México, Suplemeto G aceta de Economía, Instituto Tecnológico Autónomo de México, Año 3, Número 5.

Goodhart, C.A.E. (1995), "Money Supply Control: Base or Interest Rates?", en Hoover, K. and S. Sheffrin (eds), Montanismand the Methoddogy of Economics Cheltenham, Glos: Edward Elgar.

--, and J. Viñals (1994), "Strategy and Tactics of Monetary Policy: Examples from Europe and the Antipodes", DoumetodeTrabajo№9425, Banco de España.

Greenham, L. E. (1997), Meassismo de Transmisión de Pdítica Monetaria en Méxica Tesis, Licenciatura en Economía, ITAM.

Johnson, O . E. G. (1998), Payment Systems, Montary Pdig, and theRdeof theCentral Bank, IMF, Washington, D.C.

Kasman, B. (1992), "A Comparison of Monetary Policy Operating Procedures in Six Industrial Countries", Feekal ReseveBank of NewYokk Quartely Reiew Summer.

Leiderman, L., Liviatan, N. y A. Thorne (1995), "Shifting Nominal Anchors: The Experience of Mexico", Economa Mexicama, Nuaa Époa, vol. IV, núm. 2, México, segundo semestre.

--, and L. E. O. Svensson (1995), InflationTargds CEPR, London.

Mateos, C. y M. J. Schwartz (1997), "Metas de Inflación como Instrumento de Política Monetaria”, Doumento №. 9702, SeieDoumentos deInnestigaión, Banco de México.

Mishkin, F. S. (1996), "The Channels of Monetary Transmission: Lessons for Monetary Policy", WorkingPaper 5464, NBER.

Montador, B. (1995), "The Implementation of Monetary Policy in Canada", in Canadian Public Pdigy, March

O’Dogherty, P. (1997), "La Instrumentación de la Política Monetaria por el Banco Central", en La Pdítica Montaria en Méxica, Suplemento Gaceta de Economía, Instituto Tecnológico Autónomo de México, Año 3, Número 5. 
Ortiz, G. (1994), La Refoma Finamiera y la Desincoparaión Bancania, Fondo de Cultura Económica, México.

Pérez Porrúa, J. M. (1997), “Una Nota sobre la Indeterminación de la D emanda de Dinero de los Bancos bajo el Régimen de Encaje Cero", en La Pdítica Mondaria en México, Suplemento Gaceta de Economía, Instituto Tecnológico Autónomo de México, Año 3, Número 5.

Quepons, A. (1973), El Encaje Legl y Otras Meelidas de Contrd Utilizadas par d Banco Central, Tésis, UNAM, México.

Sellon, G. H. and S. E. Weiner (1996), "Monetary Policy Without Reserve Requirements: Analytical Issues", en EconomicReiew Federal Reserve Bank of Kansas City.

Sellon, G. H. and S. E. Weiner (1997), "Monetary Policy Without Reserve Requirements: Case Studies and Options for the United States", en Economic Review Federal Reserve Bank of Kansas City.

Summers, B.J. (1994), ThePayment System Design, Management, and Superision IMF, Washington, D.C.

Svensson, L. E. O (1994), "Monetary Policy with Flexible Exchange Rates and Forward Interest Rate Indicators, WorkingPapaer № 4633, NBER, January.

Swank, J. and L. Van Velden (1997), "Instruments, Procedures and Strategies of Monetary Policy: an Assessment of Possible Relationships for 21 OECD Countries", en Bank for International Settlements, Implementation and Tadics of Mondary Pdig, Conference Papers Vol. 3., Basle.

Taylor, J. B. (1995), "The Monetary Transmission Mechanism: An Empirical Framework", Jaumal of EconomicPespetives № 9, Fall. 